\title{
Effects of DL-2-hydroxy-4-methylthiobutyrate on the first-pass intestinal metabolism of dietary methionine and its extra-intestinal availability
}

\author{
Zhengfeng Fang ${ }^{1,2}$, Feiruo Huang ${ }^{1}$, Jie Luo ${ }^{1}$, Hongkui Wei ${ }^{1}$, Libao Ma ${ }^{1}$, Siwen Jiang ${ }^{1}$ and Jian Peng ${ }^{1}$ * \\ ${ }^{1}$ Key Laboratory of Animal Genetics, Breeding and Reproduction of Ministry of Education and Key Laboratory of Swine Genetics \\ and Breeding of Ministry of Agriculture, Department of Animal Nutrition and Feed Science, College of Animal Science and \\ Technology, Huazhong Agricultural University, Wuhan 430070, China \\ ${ }^{2}$ Key Laboratory for Animal Disease Resistance and Nutrition of the Ministry of Education of China, Animal Nutrition Institute, \\ Sichuan Agricultural University, Ya'an 625014, China
}

(Received 21 May 2009 - Revised 21 August 2009 - Accepted 24 August 2009 - First published online 12 January 2010)

The present study was conducted in a one-factorial arrangement to determine the effects of DL-2-hydroxy-4-methylthiobutyrate (DL-HMTB) on the first-pass intestinal metabolism of dietary methionine and its extra-intestinal availability. Barrows ( $n$ 6; aged $35 \mathrm{~d}$; weight $8.6 \mathrm{~kg}$ ), implanted with arterial, portal, mesenteric and gastric catheters, were fed a diet containing DL-methionine (DL-MET) or DL-HMTB once hourly and infused intramesenterically with $1 \%$-aminohippurate and intragastrically with $\left[1-{ }^{13} \mathrm{C}\right]$ methionine at $7.0 \mu \mathrm{mol} / \mathrm{kg}$ body weight per h. Arterial and portal blood samples were taken at hourly intervals until $6 \mathrm{~h}$ of tracer infusion and pigs was then killed for collection of muscle, intestine, liver and kidney samples. The net portal appearance of methionine, expressed as the fraction of ingested directly available L-methionine, was higher $(P<0 \cdot 05)$ in the DL-HMTB than in the DL-MET diet, and there was no difference $(P=0 \cdot 26)$ in the fractional portal balance of $\left[1-{ }^{13} \mathrm{C}\right]$ methionine between the diets. $\left[1-{ }^{13} \mathrm{C}\right]$ methionine enrichment (tracer:tracee ratio; mol/100 mol amino acid) in the jejunum, arterial and portal plasma, liver, kidney and muscle was also not different $(P>0.05)$ between the groups. Over the $6 \mathrm{~h}$ period after the start of feeding, the average concentration of citrulline both in the arterial and portal plasma was higher $(P<0.05)$ in the DL-HMTB than in the DL-MET group, and arterial plasma ornithine and taurine concentration was also higher $(P<0 \cdot 05)$ in the DL-HMTB than in the DL-MET group. However, plasma urea concentration both in the arterial and portal vein was lower $(P<0.05)$ in the DL-HMTB than in the DL-MET group. These results suggested that the potential difference in the first-pass use of methionine by the intestine between the DL-HMTB and DL-MET diets might affect intestinal and systemic metabolism of other amino acids, which may provide new important insights into nutritional efficiency of different methionine sources.

\section{DL-2-Hydroxy-4-methylthiobutyrate: First-pass intestinal metabolism: Extra-intestinal availability}

The small intestine is a highly differentiated and complex organ, which is not only responsible for the terminal digestion and absorption of nutrients, but also plays an important role in the synthesis, conversion and catabolism of amino acids ${ }^{(1)}$. Because the apical and basolateral membranes of each enterocyte are chemically, biochemically and physically distinct ${ }^{(2)}$, an enterocyte can selectively receive nutrients from two sources: the arterial blood across its basolateral membrane and the intestinal lumen across its brush-border membrane. Historically, it is assumed that the primary fate of essential amino acids is to protein synthesis in the target organs; however, intriguing data have demonstrated that catabolism dominates the first-pass utilisation of these amino acids by the gut $^{(3)}$. Because the extensive catabolism of dietary essential amino acids by the small intestine results in a decrease in their nutritional efficiency ${ }^{(1,3,4)}$, the question whether the catabolism of amino acids represents a functional requirement by the intestine for purposes of growth and function, or if it is driven simply by the local availability of these substrates to the mucosal enterocytes, generates particular interest among researchers in animal production and clinical treatment of gut disease.

Van der Schoor et al. ${ }^{(5)}$ indicated that amino acid oxidation by the intestine was substantially suppressed during a low protein intake. Similarly, using stable isotopes, van Goudoever et al. ${ }^{(6)}$ showed that intestinal oxidation of enteral lysine contributed one-third of total body lysine oxidation in growing pigs fed a high-protein diet, but was virtually absent in pigs fed a low-protein diet. Further study revealed that the firstpass utilisation rate of dietary lysine by the intestine was directly increased by the enteral lysine availability ${ }^{(7)}$. These results indicate adaptive regulation of intestinal protein and amino acid metabolism. Therefore, there is reason to believe that the high rate of mucosal amino acid catabolism in the intestine is under nutritional regulation, particularly by the protein intake of the animals. Considering that the small-intestinal capacity to digest and absorb protein and amino acids is substantially greater than possible dietary inputs ${ }^{(8)}$, one is

Abbreviations: BW, body weight; DL-HMTB, DL-2-hydroxy-4-methylthiobutyrate; DL-MET, DL-methionine; HMTB, 2-hydroxy-4-methylthiobutyrate; $\mathrm{pAH}, p$-aminohippurate; PPF, portal plasma flow.

* Corresponding author: Professor J. Peng, fax +8627 87281378, email pengjian@mail.hzau.edu.cn 
tempted to consider that much of this organ's demand for amino acids for maintenance may be an unnecessary burden ${ }^{(9)}$. This raises a possibility that lowering intestinal amino acid metabolism without compromising gut absorptive capacity or protective functions may be promising for improving amino acid nutritional efficiency ${ }^{(9)}$

Given evidence that intestinal metabolism of dietary amino acids is driven directly by their availability ${ }^{(5-7)}$, we hypothesised that amino acid nutritional efficiency might be improved by supplying the animal with amino acid sources more of which can bypass the intestine. Because both the D- and L- isoform of 2-hydroxy-4-methylthiobutyrate (HMTB) must be converted to L-methionine before they can be utilised by the animal ${ }^{(10)}$, and more importantly, the intestine has a much lower capacity than the liver and kidney to convert L-HMTB to L-methionine ${ }^{(11)}$, DL-2-hydroxy-4-methylthiobutyrate (DL-HMTB) may produce less L-methionine than DL-methionine (DL-MET) following transport across the intestinal cell membrane and thus may have a lower first-pass intestinal metabolism than DL-MET. Therefore, DL-HMTB and DL-MET were used in the present study to investigate the potential difference in the first-pass intestinal metabolism and extra-intestinal availability of dietary methionine which was supplied by different methionine sources. Additionally, considering that methionine may be the limiting amino acid on the basis of its net portal appearance ${ }^{(3)}$, the arterial and portal plasma concentrations of citrulline, ornithine, taurine and urea were also determined to evaluate the effect of first-pass metabolism of dietary methionine sources by the intestine on the intestinal metabolism of other amino acids.

\section{Materials and methods}

\section{Animals and diets}

Piglets ( $n$ 10), aged $21 \mathrm{~d}$, from the same litter $(6 \cdot 3$ (SD $1 \cdot 1) \mathrm{kg}$ body weight $(\mathrm{BW})$, Large White $\times$ Landrace) were individually housed in metabolism cages $(1.5 \mathrm{~m} \times 0.75 \mathrm{~m})$ located in the same air-conditioned room. Pigs were fed one of two diets (DL-HMTB $v$. DL-MET diet) with five pigs per diet during the experimental period from age $21 \mathrm{~d}$ to age $35 \mathrm{~d}$. The two diets (Table 1), formulated to meet National Research Council $^{(12)}$ nutrient requirements, had the same amounts of maize, dried whey, porcine plasma and dehulled soyabean meal. The only difference between the two diets was that $30 \%$ of the total dietary methionine was provided by DL-HMTB and DL-MET, respectively. Pigs were fed quarter of the daily meal at $08.00,12.00,16.00$ and 20.00 hours, respectively, and the daily feed intake was, as recommended by previous studies ${ }^{(3,7)}$, at a rate of $50 \mathrm{~g}$ feed $/ \mathrm{kg} \mathrm{BW}$ per $\mathrm{d}$, which supplied $8.81 \mathrm{~g}$ crude protein $/ \mathrm{kg}$ per $\mathrm{d}$ and $725 \mathrm{~kJ}$ gross energy/kg per d. Pigs had free access to water at all times. After a $7 \mathrm{~d}$ adaption period, all pigs received surgery as described $^{(13)}$. Briefly, after overnight food deprivation, pigs were surgically implanted with catheters in one carotid artery (Tygon tubing; $2.41 \mathrm{~mm}$ outer diameter (o.d.)), the portal vein (polyethylene tubing; $1.78 \mathrm{~mm}$ o.d.), the mesenteric vein (silicone tubing; $1.02 \mathrm{~mm}$ o.d.) and the stomach lumen (silicone tubing; $2.67 \mathrm{~mm}$ o.d.), about $2 \mathrm{~cm}$ from the pyloric sphincter, under isoflurane anaesthesia and strict aseptic conditions.
Table 1. Composition of experimental diets (as-fed basis)

\begin{tabular}{|c|c|}
\hline & Content \\
\hline \multicolumn{2}{|l|}{ Ingredients (\%) } \\
\hline Maize & $68 \cdot 13$ \\
\hline Dried whey & $11 \cdot 50$ \\
\hline Soyabean oil & $2 \cdot 00$ \\
\hline Dehulled soyabean meal & 4.50 \\
\hline Porcine plasma & $10 \cdot 00$ \\
\hline Methionine premix* & 0.14 \\
\hline Lysine $\mathrm{HCl}$ & 0.45 \\
\hline Threonine & $0 \cdot 10$ \\
\hline Tryptophan & 0.01 \\
\hline Isoleucine & $0 \cdot 17$ \\
\hline Valine & 0.05 \\
\hline Limestone & $1 \cdot 02$ \\
\hline Dicalcium phosphate & $1 \cdot 14$ \\
\hline Vitamin premix $†$ & $0 \cdot 30$ \\
\hline Mineral premix $\ddagger$ & 0.49 \\
\hline Total & 100 \\
\hline \multicolumn{2}{|c|}{ Amino acid concentration ( $\mathrm{g} / \mathrm{kg}$ protein)§ } \\
\hline Threonine & 56 \\
\hline Tryptophan & 16 \\
\hline Leucine & 84 \\
\hline Lysine & 84 \\
\hline Phenylalanine & 52 \\
\hline Valine & 58 \\
\hline Methionine & 22 \\
\hline Isoleucine & 46 \\
\hline Histidine & 31 \\
\hline Proline & 52 \\
\hline Arginine & 55 \\
\hline Tyrosine & 28 \\
\hline Cysteine & 28 \\
\hline Alanine & 60 \\
\hline Serine & 53 \\
\hline Glutamate plus glutamine & 149 \\
\hline Aspartate plus asparagine & 85 \\
\hline Glycine & 41 \\
\hline \multirow{2}{*}{\multicolumn{2}{|c|}{$\begin{array}{l}\text { * Supplied } 0.12 \% \text { methionine activity at the expense of maize as DL-methionine } \\
(99 \%) \text { or Alimet }{ }^{\circledR}(88 \% \text {, DL-2-hydroxy-4-methylthiobutyrate; Novus International, } \\
\text { St Louis, MO, USA). } \\
\text { †Provided (per kg diet): retinol, } 4050 \mu \mathrm{g} \text {; vitamin } \mathrm{D}_{3}, 75 \mu \mathrm{g} \text {; vitamin } \mathrm{E}, 24 \mathrm{mg} \text {; } \\
\text { menadione, } 3 \mathrm{mg} \text {; thiamine, } 3 \mathrm{mg} \text {; riboflavin, } 7.5 \mathrm{mg} \text {; niacin, } 30 \mathrm{mg} \text {; d-pantothe- } \\
\text { nic acid, } 15 \mathrm{mg} \text {; vitamin } \mathrm{B}_{6}, 3 \mathrm{mg} \text {; vitamin } \mathrm{B}_{12}, 22.5 \mu \mathrm{g} \text {; d-biotin, } 120 \mu \mathrm{g} \text {; folic } \\
\quad \text { acid, } 1.5 \mathrm{mg} \text {. } \\
\text { † Provided (per kg diet): Cu, } 140 \mathrm{mg} \text {; Fe, } 150 \mathrm{mg} \text {; Mn, } 50 \mathrm{mg} \text {; Zn, } 140 \mathrm{mg} \text {; I, } 0.8 \mathrm{mg} \text {; } \\
\text { Se, } 0.4 \mathrm{mg} \text {; flavours, } 200 \mathrm{mg} \text {; antioxidant, } 100 \mathrm{mg} \text {. }\end{array}$}} \\
\hline & \\
\hline \multicolumn{2}{|c|}{$\S$ The crude protein content was analysed to be $176 \mathrm{~g} / \mathrm{kg}$ diet. } \\
\hline
\end{tabular}

The catheters were filled with sterile saline containing heparin $\left(2.0 \times 10^{5} \mathrm{U} / \mathrm{l}\right)$. All of the catheters were protected with gauze pads and secured with an elastic bandage. The animals received an intramuscular injection of analgesic $(0.1 \mathrm{mg}$ butorphenol tartrate $/ \mathrm{kg}$ ) and antibiotic (20 mg ampicillin sodium $/ \mathrm{kg}$ ) twice daily during the first $3 \mathrm{~d}$ post-surgery. After the surgery, the piglets were offered parenteral nutrition for about $12-24 \mathrm{~h}$ and were then progressively returned to their preceding level of dietary intake for $\geq 5 \mathrm{~d}$ before the experimental protocol. At the postnatal age of $35 \mathrm{~d}$, six barrows in good health and with well-kept catheters were studied for a $7 \mathrm{~h}$ experimental period. Their BW was 8.6 (SD 1.4) kg.

\section{Infusion protocol and blood collection}

The piglets were deprived of feed from 18.00 to 08.00 hours. At 06.55 hours, a $1 \%$ solution of $p$-aminohippurate $(\mathrm{pAH}$, $\mathrm{Na}$ salt, diluted in sterile saline at $\mathrm{pH} 7 \cdot 5$ ) was infused 
continuously with a screw-driven syringe constant-infusion pump (WZS-50F6; Medical Instrument Corporation of Zhejiang University, China) into the mesenteric catheters at a rate of $3.820 \mathrm{ml} / \mathrm{min}$ for $5 \mathrm{~min}$ and then $0.788 \mathrm{ml} / \mathrm{min}$ for $7 \mathrm{~h}^{(14)}$. At about 07.45 hours, baseline arterial and portal blood samples $(10 \mathrm{ml})$ were withdrawn into heparinised tubes. From 08.00 to 14.00 hours, pigs were offered meals at hourly intervals, and the meal was the equivalent of one twenty-fourth of the daily intake $(45 \mathrm{~g} / \mathrm{kg} \mathrm{BW})$. Immediately after the first meal, piglets received a constant infusion of $\left[1-{ }^{13} \mathrm{C}\right]$ methionine, suspended in water via the gastric catheter at a rate of about $0.25 \mathrm{ml} / \mathrm{min}$ to provide $\left[1-{ }^{13} \mathrm{C}\right]$ methionine at $7 \cdot 0 \mu \mathrm{mol} / \mathrm{kg} \mathrm{BW}$ per $\mathrm{h}$. After the tracer infusion was started, the piglets continued to receive hourly meals. Arterial and portal blood samples were taken at hourly intervals until $6 \mathrm{~h}$ of tracer infusion, and all the blood samples were immediately placed on ice. Within 10 min of collection, the blood was centrifuged at $4^{\circ} \mathrm{C}$ and $2550 \mathrm{~g}$ for $15 \mathrm{~min}$ to separate plasma from cells. A sample of plasma was refrigerated and assayed within $24 \mathrm{~h}$ for $\mathrm{pAH}$ concentration. Another sample was stored at $-80^{\circ} \mathrm{C}$ until analysed for amino acid concentration.

\section{Collection of tissue samples}

Immediately after completion of blood samples, pigs were killed with an arterial injection of sodium pentobarbital $(50 \mathrm{mg} / \mathrm{kg} \mathrm{BW})$ and sodium phenytoin $(5 \mathrm{mg} / \mathrm{kg} \quad \mathrm{BW})$. Immediately after death, the animals were rinsed with $70 \%$ ethanol, the longissimus dorsi muscle was collected rapidly, then the abdomen was opened, and intestinal tissue samples were collected as described ${ }^{(15)}$. Briefly, the intestine was rapidly excised from the ligament of Treitz to the ileocaecal valve, freed of its mesenteric fat, and rinsed in ice-cold saline. The intestine was divided into three segments, with the most proximal and distal segments representing the jejunum and ileum, respectively. A $2 \mathrm{~cm}$ section of tissue was taken at a predetermined distance from the two ends of the intestines, snap-frozen in liquid $\mathrm{N}_{2}$, and stored at $-80^{\circ} \mathrm{C}$ for subsequent RNA isolation. The samples of liver and kidney were collected as described previously ${ }^{(16)}$. Samples were obtained as quickly as possible, snap-frozen in liquid $\mathrm{N}_{2}$, and stored at $-80^{\circ} \mathrm{C}$ for subsequent analysis.

\section{p-Aminohippurate analysis}

pAH in plasma samples was analysed as described ${ }^{(13)}$. The portal plasma flow (PPF) rate (litres/kg per h) was calculated as the following equation:

$$
\mathrm{PPF}=\mathrm{C}_{\mathrm{i}} \times \mathrm{IR} /\left(\left(\mathrm{pAH}_{\mathrm{p}}-\mathrm{pAH}_{\mathrm{a}}\right) \times \mathrm{BW}\right),
$$

where $\mathrm{C}_{\mathrm{i}}$ is the concentration of infused $\mathrm{pAH}$ solution $(\mathrm{g} / \mathrm{l}), \mathrm{IR}$ is the infusion rate (litres/h) of $\mathrm{pAH}, \mathrm{pAH}_{\mathrm{p}}$ and $\mathrm{pAH}_{\mathrm{a}}$ are the concentration $(\mathrm{g} / \mathrm{l})$ of $\mathrm{pAH}$ detected in the portal vein and artery, respectively; $\mathrm{BW}$ is measured in $\mathrm{kg}$.

\section{Amino acid analysis}

For amino acid analysis, the diet was hydrolysed in $6 \mathrm{M}-\mathrm{HCl}$ for $24 \mathrm{~h}$ at $110^{\circ} \mathrm{C}$, and the frozen plasma samples were thawed at $4^{\circ} \mathrm{C}$ and deproteinised using $2.5 \mathrm{ml}$ of $7.5 \%(\mathrm{w} / \mathrm{v})$ TCA per $\mathrm{ml}$ plasma. For methionine and cysteine analysis, the dietary protein was oxidised with performic acid for $16 \mathrm{~h}$ at $4^{\circ} \mathrm{C}$ before hydrolysis in $6 \mathrm{M}-\mathrm{HCl}$ for $24 \mathrm{~h}$ at $110^{\circ} \mathrm{C}$. The amino acid concentration of deproteinised plasma and hydrolysed protein was determined by ion-exchange chromatography with an L8800 high-speed amino acid analyser (Hitachi, Tokyo, Japan).

\section{Measurement of stable isotope tracer enrichments}

Plasma preparation. Plasma isotopic enrichment of $\left[1-{ }^{13} \mathrm{C}\right]$ methionine was quantified on the ethyl chloroformate derivatives by GC-MS using a modification of the methods described previously ${ }^{(17,18)}$. A quantity of $200 \mu$ plasma was acidified with $200 \mu \mathrm{l} 10 \%$ TCA, centrifuged (10000 $\mathrm{g}$; $10 \mathrm{~min}$ ) and the supernatant fraction was added to $0.5 \mathrm{ml}$ Dowex cation-exchange resin (AG 50W-X8 100-200 mesh, hydrogen form; Bio-Rad Laboratories, Richmond, CA, USA). Resin was washed four times with $1 \mathrm{ml}$ of $0.01 \mathrm{M}-\mathrm{HCl}$ and eluted three times with $1 \mathrm{ml}$ of $5 \mathrm{M}-\mathrm{NH}_{4} \mathrm{OH}$ and once with $1 \mathrm{ml}$ distilled water into $4 \mathrm{ml}$ vials. Vials were dried by Speed-Vac lyophilisation (Bachofer, Reutlingen, Germany). The purified amino acids were then derivatised to their $N(O, S)$ ethoxycarbonyl ethyl ester derivatives following the protocol as described previously ${ }^{(19)}$. In brief, amino acids in residues were treated with $100 \mu$ l of water-ethanol-pyridine $(60: 32: 8$, by vol.). Then $10 \mu$ l of ethyl chloroformate (Fluka, Shanghai, China) was added and mixed by shaking the tube gently for $10 \mathrm{~s}$. The derivatives were extracted with $150 \mu \mathrm{l}$ of chloroform (containing $10 \mathrm{ml}$ ethyl chloroformate/l). A sample $(1 \mu \mathrm{l})$ was taken from the chloroform layer and injected.

Tissue preparation. The liver, kidney, muscle and jejunum tissues were homogenised into 4 volumes of chilled water. A sample of $1 \mathrm{ml}$ of these tissue homogenates was deproteinised with $1 \mathrm{ml}$ of $6 \%$ sulfosalicylic acid and centrifuged $(15000 \mathrm{~g}$; $10 \mathrm{~min}$ ). The resulting precipitate was hydrolysed for $24 \mathrm{~h}$ at $110^{\circ} \mathrm{C}$. The hydrolysate and the supernatant fraction obtained in the deproteinisation procedure were subjected to Dowex cation exchange as described earlier. The eluant from the column was freeze-dried by vacuum and samples were derivatised using ethyl chloroformate as described earlier.

$G C-M S$ conditions. GC-MS analysis was carried out on a Varian CP-3800 gas chromatograph (Varian, Inc., Palo Alto, CA, USA) equipped with a $30 \mathrm{~m} \times 0.25 \mathrm{~mm} \times 0.25 \mu \mathrm{m}$ VF-5ms capillary column and interfaced with a Saturn 2200 MS-Engine (Varian, Inc.). The GC conditions were as follows: carrier gas, $\mathrm{He}$; column head pressure, $70 \mathrm{kPa}$; injector temperature, $250^{\circ} \mathrm{C}$; oven temperature gradient program, $120^{\circ} \mathrm{C}$ increased to $280^{\circ} \mathrm{C}$ at $25^{\circ} \mathrm{C} / \mathrm{min}$; interface temperature, $250^{\circ} \mathrm{C}$. Electron impact-MS conditions were as follows: source temperature, $250^{\circ} \mathrm{C}$; analyser temperature, $120^{\circ} \mathrm{C}$; electron energy, $70 \mathrm{eV}$. Ion abundance was monitored with selected-ion monitoring; mass:charge $(\mathrm{m} / \mathrm{z})$ ratio for natural methionine $[\mathrm{M}+0]$ and $\left[1-{ }^{13} \mathrm{C}\right]$ methionine $[\mathrm{M}+1]$ were 249 and 250 respectively. All samples were measured in triplicate.

\section{Calculations}

Net portal amino acid balances ( $\mu \mathrm{mol} / \mathrm{kg}$ per $\mathrm{h}$ ) were calculated by the following formula:

$$
\operatorname{PPF} \times\left(\mathrm{C}_{\mathrm{p}}-\mathrm{C}_{\mathrm{a}}\right)
$$


where PPF is in litres/kg per $\mathrm{h}$, and $\mathrm{C}_{\mathrm{p}}$ and $\mathrm{C}_{\mathrm{a}}$ are the portal and arterial plasma concentrations of amino acids $(\mu \mathrm{mol} / \mathrm{l})$, respectively.

Portal tracer amino acid balances $\left(\mu \mathrm{mol}\left[1-{ }^{13} \mathrm{C}\right]\right.$ methionine/ $\mathrm{kg}$ per h) were calculated by the following formula:

$$
\mathrm{PPF} \times\left(\left(\mathrm{C}_{\mathrm{p}} \times t / T_{\mathrm{p}}-\mathrm{C}_{\mathrm{a}} \times t / T_{\mathrm{a}}\right)\right),
$$

Where $t / T$ is the tracer $\left(\left[1-{ }^{13} \mathrm{C}\right]\right.$ methionine):tracee $\left(\left[1-{ }^{12} \mathrm{C}\right]\right.$ methionine) ratio.

$$
\begin{gathered}
\text { Fractional mass balance (percentage of intake) } \\
=\text { portal balance } \times 100 / \text { input. }
\end{gathered}
$$

For the portal methionine balance calculations, input is the intake of directly available L-methionine, which amounted to $85 \%$ of the total methionine (dietary L-methionine plus D-MET) in the DL-MET diet and $70 \%$ of the total methionine (dietary L-methionine plus DL-HMTB) in the DL-HMTB diet, and for the portal tracer methionine balance calculations, input is the rate of infusion of tracer methionine.

\section{Statistics}

All concentrations, tracer:tracee ratios and portal balances are presented as mean values and the between-animal standard deviations. Methionine concentrations in the arterial and portal plasma and differences in means of portal balances were compared between the DL-MET and DL-HMTB groups for the $6 \mathrm{~h}$ infusion period by two-way ANOVA for repeated measures, and post hoc analysis was conducted using Dunnett's procedures (SAS statistical package, version 8.1; SAS Institute Inc., Cary, NC, USA). The main effects on tracer methionine enrichment consisted of tissue and treatment and were analysed using the general linear model procedures of SAS (version 8.1; SAS Institute Inc.). Least-squares means comparison was used to evaluate differences among tissues and between treatments for tracer methionine enrichment. $P$ values $\leq 0.05$ were considered statistically significant.

\section{Ethics approval}

All experimental procedures involving animals were approved by the Animal Care and Use Committee of the College of Animal Sciences and Technology, Huazhong Agricultural University, and were carried out in accordance with the National Research Council's Guide for the Care and Use of Laboratory Animals.

\section{Results}

First-pass intestinal metabolism and net portal appearance of methionine

The net portal balances of methionine in piglets fed once hourly with DL-MET or DL-HMTB are presented in Fig. 1. Regardless of treatment, a rapid and significant $(P<0 \cdot 05)$ increase in the net portal balance of methionine was observed within the $0-2 \mathrm{~h}$ after the start of feeding. The net portal balance of dietary methionine, escaping the intestinal first-pass use, remained stable at a level of about 20-25 and about $25-30 \mu \mathrm{mol} / \mathrm{kg}$ per $\mathrm{h}$ in the DL-MET and DL-HMTB groups,

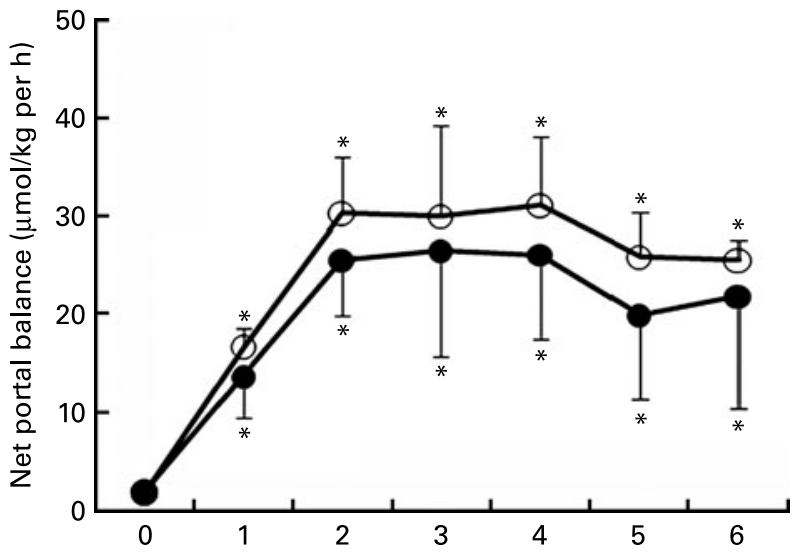

Fig. 1. Net portal balance ( $\mu \mathrm{mol} / \mathrm{kg}$ per $\mathrm{h}$ ) of methionine in piglets fed DLmethionine (--) or DL-2-hydroxy-4-methylthiobutyrate (-O-) once hourly. Values are means, with standard deviations represented by vertical bars. ${ }^{*}$ Mean value was significantly different from that at baseline $(0 \mathrm{~h})(P<0.05)$.

respectively, between 2 and $6 \mathrm{~h}$ after the first meal. There was no significant $(P>0.05)$ difference in the portal balance between the treatments at each time period evaluated. Methionine concentrations in the portal (Fig. 2(a)) and arterial (Fig. 2(b)) plasma were also not different $(P>0.05)$ between treatments over the $6 \mathrm{~h}$ period. However, time had a significant $(P<0.05)$ effect on methionine concentrations in both the portal and arterial plasma. Compared with the baseline $(0 \mathrm{~h})$ methionine concentration, a significant $(P<0 \cdot 05)$ increase was observed in the portal and arterial plasma within $2-5 \mathrm{~h}$ and $3-4 \mathrm{~h}$, respectively. The intake of directly available L-methionine was 36.8 (SD 1.0) $\mu \mathrm{mol} / \mathrm{kg}$ per $\mathrm{h}$ in the DL-MET diet and $31.5(\mathrm{SD} 3.6) \mu \mathrm{mol} / \mathrm{kg}$ per $\mathrm{h}$ in the DL-HMTB diet, and the net portal appearance of methionine, expressed as the fraction of ingested directly available L-methionine, was significantly $(P<0.05)$ higher in the DL-HMTB than in the DL-MET diet over the time courses evaluated (Fig. 3).

The portal tracer balance for methionine over the last $1 \mathrm{~h}$ is presented in Table 2. The fractional portal balance of tracer methionine was $67 \%$ in the DL-MET group and $71 \%$ in the DL-HMTB group, with no significant $(P>0.05)$ difference between the treatments, which meant that the proportion of methionine that was utilised in the first pass by the intestine was 33 and $29 \%$ in the DL-MET and DL-HMTB groups, respectively.

Net portal balance and plasma concentrations of citrulline, ornithine, taurine and urea

As shown in Table 3, the average concentration of citrulline both in the arterial and portal plasma was significantly $(P<0.05)$ higher in the DL-HMTB group than in the DL-MET group over the $6 \mathrm{~h}$ period. Both ornithine and taurine concentrations in the arterial plasma of the DL-HMTB group were also significantly $(P<0.05)$ higher than those of the DL-MET group over the $6 \mathrm{~h}$ period. Remarkably, over all of the time courses evaluated, the average concentration of urea both in the arterial and portal plasma was significantly $(P<0.05)$ lower in the DL-HMTB than in the DL-MET group. However, there were no differences $(P>0.05)$ in the 

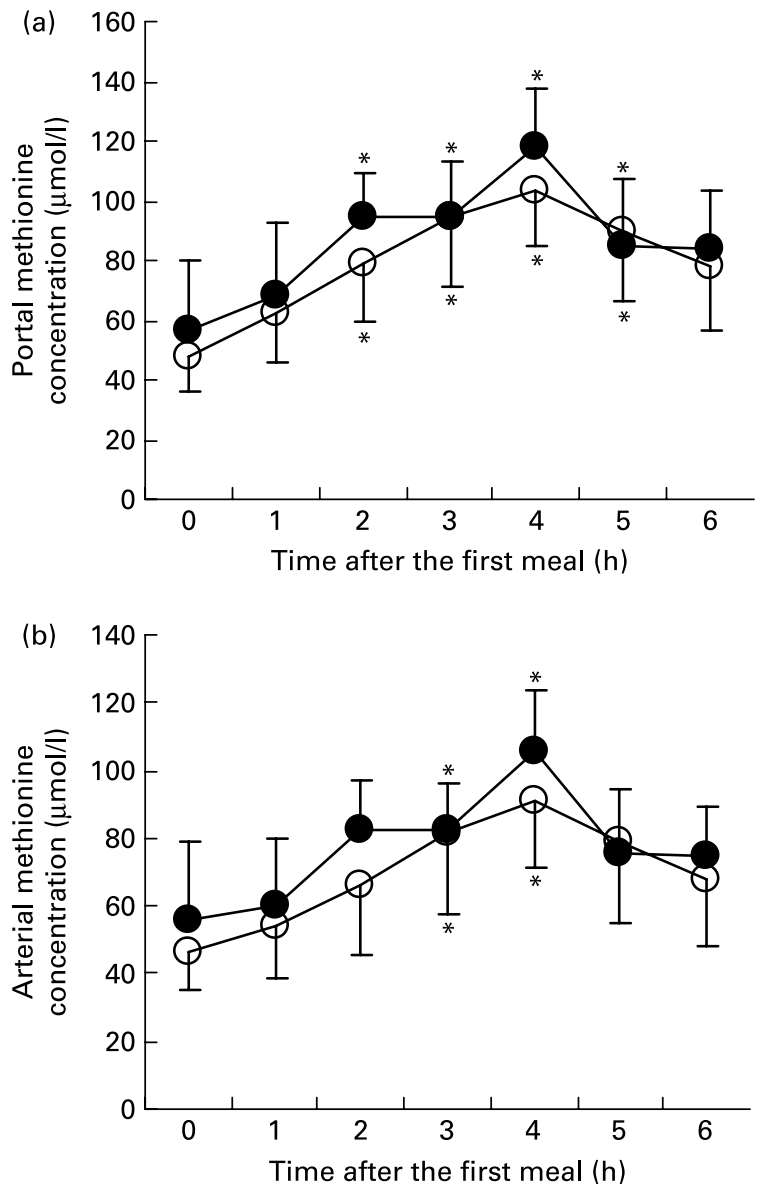

Fig. 2. Methionine concentration $(\mu \mathrm{mol} / \mathrm{l})$ in the portal (a) and arterial (b) plasma of piglets fed DL-methionine (- -) or DL-2-hydroxy-4-methylthiobutyrate (-O-) once hourly. Values are means, with standard deviations represented by vertical bars. * Mean value was significantly different from that at baseline $(0 \mathrm{~h})(P<0.05)$.

net portal balance of citrulline, ornithine, taurine or urea between the treatment groups (Table 4).

\section{Distribution of tracer methionine enrichment in the piglets}

The isotopic enrichments (tracer:tracee ratio; mol/100 mol amino acid) of $\left[1-{ }^{13} \mathrm{C}\right]$ methionine in the jejunum, liver, kidney, muscle and arterial plasma of piglets fed DL-MET or DL-HMTB once hourly are presented in Table 5. Arterial plasma had a significantly $(P<0.05)$ higher tracer methionine enrichment than the tissues. Among the tissues evaluated, the highest and lowest tracer methionine enrichment was observed in the muscle and intestine, respectively, regardless of treatments. Dietary treatment had no significant $(P>0.05)$ effect on the tracer methionine enrichments. Tracer methionine enrichments in the liver and muscle tended $(P=0 \cdot 10)$ to be higher in the DL-HMTB than in the DL-MET group.

\section{Discussion}

The net portal appearance of dietary amino acids is dependent on the degree to which they are utilised in the first pass by the enterocyte and thus has been commonly used as an indicator

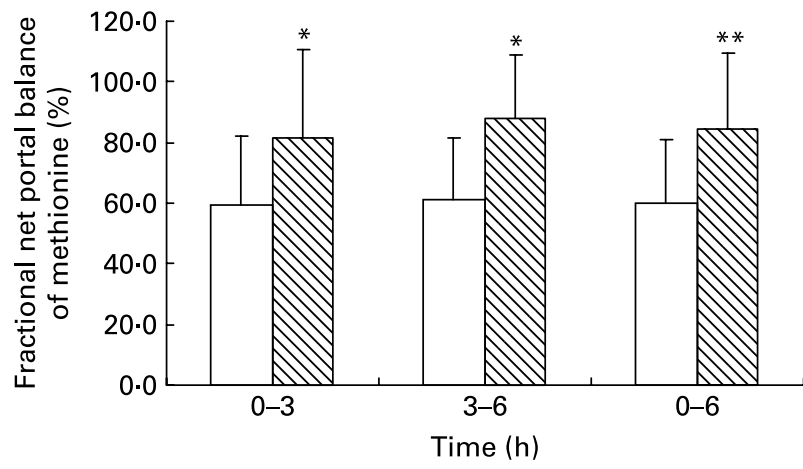

Fig. 3. The fractional net portal balance of methionine (percentage of intake $=$ portal balance $\times 100 /$ input) in piglets fed DL-methionine (DL-MET; $\square$ )

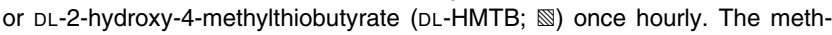
ionine input in the DL-MET and DL-HMTB diets is estimated to be 36.8 (SD 1.0) and 31.5 (SD 3.6) $\mu \mathrm{mol} / \mathrm{kg}$ per $\mathrm{h}$, which is equal to 85 and $70 \%$, respectively, of the total methionine (dietary L-methionine plus DL-MET or DL-HMTB) intake. Values are means, with standard deviations represented by vertical bars. Mean value was significantly different from that for the DL-MET diet: ${ }^{*} P<0.05,{ }^{* *} P<0.01$.

for the evaluation of intestinal metabolism and extra-intestinal availability of dietary amino acids ${ }^{(3)}$. In another part of this study, we reported that the fractional portal balance of $\mathrm{L}$-methionine over the $6 \mathrm{~h}$ period was not different between the DL-HMTB and DL-MET groups ${ }^{(13)}$. However, because it was not known how much D-MET or DL-HMTB was converted to L-methionine when they were transported across the enterocytes, the input of L-methionine in the calculation of the fractional portal balance was estimated according to the total methionine (dietary L-methionine plus D-MET or DL-HMTB). This may result in an underestimate of the fractional portal balance of methionine in one or both of the two diets, which may mask the difference between the groups. With this in mind, the net portal appearance of methionine, expressed as the fraction of ingested directly available L-methionine, was examined in the present study. The results indicated that the fractional portal methionine balance was higher in the DL-HMTB than in the DL-MET diet. Although the similar portal mass balance combined with the relatively lower input of directly available L-methionine in the DL-HMTB than in the DL-MET diet may in part account for the difference in the fractional portal balance between the treatments, it did not exclude the possibility that the DL-HMTB diet had a lower first-pass metabolism of methionine by the intestine than the DL-MET diet. This notion was supported by the evidence that the trans-sulfuration reaction of methionine in splanchnic tissues was affected by dietary methionine levels ${ }^{(20)}$. Because methionine converted from the sources was not included in the calculated methionine input, which may result in overestimate of the fractional portal balance of dietary methionine, the stable isotope tracer methionine $\left(\left[1-{ }^{13} \mathrm{C}\right]\right.$ methionine $)$ was used in the present study to further estimate the proportion of L-methionine that was utilised in the first pass by the intestine. The results revealed that the fractional portal balance of $\left[1-{ }^{13} \mathrm{C}\right]$ methionine in the DL-MET and DL-HMTB diets was 67 and $71 \%$, respectively, which meant that 33 and $29 \%$ of $\left[1-{ }^{13} \mathrm{C}\right]$ methionine was utilised by the intestine in the first pass. These results indicated that, despite the difference in methionine 
Table 2. The doses, arterial and portal plasma tracer:tracee ratios and portal balances of $\left[1-{ }^{13} \mathrm{C}\right] \mathrm{methionine}$ in piglets fed DL-methionine (DL-MET) or DL-2-hydroxy-4-methylthiobutyrate (DL-HMTB) once hourly

(Mean values and standard deviations)

Tracer:tracee ratio $(\mathrm{mol} / 100 \mathrm{~mol}$ amino acid)

\begin{tabular}{|c|c|c|c|c|c|c|c|c|c|c|}
\hline \multirow[b]{2}{*}{ Diet } & \multicolumn{2}{|c|}{$\begin{array}{c}\text { Intake } \\
(\mu \mathrm{mol} / \mathrm{kg} \text { per } \mathrm{h})\end{array}$} & \multicolumn{2}{|c|}{ Arterial } & \multicolumn{2}{|c|}{ Portal } & \multicolumn{2}{|c|}{$\begin{array}{l}\text { Portal tracer balance } \\
(\mu \mathrm{mol} / \mathrm{kg} \text { per } \mathrm{h})\end{array}$} & \multicolumn{2}{|c|}{$\begin{array}{l}\text { Portal tracer bal- } \\
\text { ance as proportion } \\
\text { of intake }(\%)\end{array}$} \\
\hline & Mean & SD & Mean & SD & Mean & SD & Mean & SD & Mean & SD \\
\hline DL-MET & 7.01 & 0.31 & 5.46 & 0.36 & $7 \cdot 58$ & 0.56 & 4.71 & 0.27 & 67 & 5 \\
\hline DL-HMTB & $7 \cdot 01$ & 0.19 & $5 \cdot 77$ & 0.37 & $7 \cdot 48$ & 0.64 & 4.95 & 0.28 & 71 & 4 \\
\hline$P$ & \multicolumn{2}{|c|}{0.99} & \multicolumn{2}{|c|}{0.21} & \multicolumn{2}{|c|}{0.79} & \multicolumn{2}{|c|}{0.15} & \multicolumn{2}{|c|}{0.26} \\
\hline
\end{tabular}

sources, the first-pass utilisation of dietary methionine by the intestine remained at about $30 \%$ of intake. Similar results in piglets fed milk protein have been obtained in a previous study $^{(7)}$, in which dietary methionine intake is about $1 \cdot 5$-fold that in the present study. These results suggested that the fraction of methionine may be more constant than the absolute amount of methionine that is extracted by the intestine in its first-pass. This notion was further supported by the unexpected results that the isotope enrichment in plasma and tissues evaluated was similar between the present and a previous study ${ }^{(17)}$, although the infused isotope flow $(7.0 \mu \mathrm{mol} / \mathrm{kg}$ per $\mathrm{h}$ ) in the present study is only $70 \%$ of that used in the previous study $^{(17)}$. That the total methionine input in the present study was also about $70 \%$ of that administrated in the previous study ${ }^{(17)}$ may in part account for the similarity of the results between ours and the previous study ${ }^{(17)}$. It would appear that the higher input of directly available L-methionine in the DL-MET than in the DL-HMTB diet combined with the similar fraction of L-methionine that was utilised by the intestine in the first pass might account for the similar portal mass balance and thus a lower fractional portal balance of L-methionine in the DL-MET than in the DL-HMTB diet.
In addition to the difference in the net portal appearance of methionine (expressed as the fraction of ingested directly available L-methionine), significant differences in the firstpass use of some other amino acids between the DL-HMTB and DL-MET diets have been observed in our previous study ${ }^{(13)}$. Particularly, compared with DL-MET-fed pigs, pigs fed the DL-HMTB diet had increased net portal balances of leucine, isoleucine, histidine, arginine and alanine, but had a decreased portal appearance of glutamate over a $6 \mathrm{~h}$ period $^{(13)}$. Therefore, a second endpoint in the present study was to determine whether the changed metabolism of dietary amino acids was also reflected in the change of concentrations of metabolites deriving from the metabolism of these amino acids. It is established that in addition to arginine synthesis, glutamine/glutamate and proline are also the major precursors for citrulline synthesis ${ }^{(21,22)}$. Thus, the increased portal plasma concentration of citrulline may provide a direct evidence for the increased degradation of glutamate in DL-HMTB-fed piglets. Furthermore, given that the citrulline released by the small intestine is not taken up by the liver, and is utilised for arginine synthesis primarily in the kidneys ${ }^{(23)}$, the increased citrulline concentration in the arterial plasma may

Table 3. The average concentration ( $\mu \mathrm{mol} / \mathrm{l})$ of citrulline, ornithine, taurine and urea in the arterial and portal plasma of piglets fed DL-methionine (DL-MET) or DL-2-hydroxy-4-methylthiobutyrate (DL-HMTB) once hourly

(Mean values and standard deviations)

\begin{tabular}{|c|c|c|c|c|c|c|c|c|c|c|c|c|}
\hline \multirow[t]{3}{*}{ Tracer infusion... } & \multicolumn{4}{|c|}{$0-3 h$} & \multicolumn{4}{|c|}{$3-6 h$} & \multicolumn{4}{|c|}{$0-6 \mathrm{~h}$} \\
\hline & \multicolumn{2}{|c|}{ Arterial } & \multicolumn{2}{|c|}{ Portal } & \multicolumn{2}{|c|}{ Arterial } & \multicolumn{2}{|c|}{ Portal } & \multicolumn{2}{|c|}{ Arterial } & \multicolumn{2}{|c|}{ Portal } \\
\hline & Mean & SD & Mean & SD & Mean & SD & Mean & SD & Mean & SD & Mean & SD \\
\hline \multicolumn{13}{|l|}{ Citrulline } \\
\hline DL-MET & 54 & 33 & 76 & 35 & 61 & 33 & 73 & 37 & 57 & 33 & 75 & 34 \\
\hline DL-HMTB & 74 & 20 & 100 & 28 & 86 & 19 & 103 & 35 & 79 & 20 & 101 & 30 \\
\hline$P$ & \multicolumn{2}{|c|}{0.115} & \multicolumn{2}{|c|}{0.112} & \multicolumn{2}{|c|}{0.115} & \multicolumn{2}{|c|}{0.149} & \multicolumn{2}{|c|}{0.025} & \multicolumn{2}{|c|}{0.031} \\
\hline \multicolumn{13}{|l|}{ Ornithine } \\
\hline DL-MET & 45 & 9 & 61 & 8 & 50 & 10 & 66 & 13 & 47 & 9 & 63 & 10 \\
\hline DL-HMTB & 50 & 8 & 64 & 8 & 62 & 6 & 71 & 6 & 55 & 9 & 67 & 8 \\
\hline$P$ & \multicolumn{2}{|c|}{0.160} & \multicolumn{2}{|c|}{0.402} & \multicolumn{2}{|c|}{0.009} & \multirow{2}{*}{\multicolumn{2}{|c|}{0.256}} & \multirow{2}{*}{\multicolumn{2}{|c|}{0.004}} & \multicolumn{2}{|c|}{0.142} \\
\hline \multicolumn{10}{|l|}{ Taurine } & & & \\
\hline DL-MET & 46 & 8 & 59 & 15 & 42 & 8 & 53 & 12 & 44 & 8 & 56 & 14 \\
\hline DL-HMTB & 56 & 15 & 68 & 22 & 47 & 12 & 61 & 10 & 53 & 14 & 65 & 18 \\
\hline$P$ & \multicolumn{2}{|c|}{0.075} & \multicolumn{2}{|c|}{0.294} & \multicolumn{2}{|c|}{0.357} & \multicolumn{2}{|c|}{0.174} & \multicolumn{2}{|c|}{0.045} & \multicolumn{2}{|c|}{0.111} \\
\hline \multicolumn{13}{|l|}{ Urea } \\
\hline DL-MET & 2373 & 270 & 2798 & 415 & 2326 & 561 & 2830 & 713 & 2352 & 408 & 2812 & 546 \\
\hline DL-HMTB & 1692 & 643 & 1993 & 814 & 1397 & 442 & 1932 & 567 & 1566 & 572 & 1967 & 703 \\
\hline$P$ & \multicolumn{2}{|c|}{0.009} & & & & & & & & & & \\
\hline
\end{tabular}


Table 4. The net portal balance ( $\mu \mathrm{mol} / \mathrm{kg}$ per $\mathrm{h}$ ) of citrulline, ornithine, taurine and urea in piglets fed DL-methionine (DL-MET) or DL-2-hydroxy4-methylthiobutyrate (DL-HMTB) once hourly

(Mean values and standard deviations)

\begin{tabular}{|c|c|c|c|c|c|c|}
\hline \multirow[t]{2}{*}{ Tracer infusion... } & \multicolumn{2}{|c|}{$0-3 h$} & \multicolumn{2}{|c|}{$3-6 h$} & \multicolumn{2}{|c|}{$0-6 \mathrm{~h}$} \\
\hline & Mean & SD & Mean & SD & Mean & SD \\
\hline \multicolumn{7}{|l|}{ Citrulline } \\
\hline DL-MET & 43 & 29 & 26 & 15 & 36 & 25 \\
\hline DL-HMTB & 52 & 21 & 42 & 47 & 48 & 34 \\
\hline$P$ & \multicolumn{2}{|c|}{0.464} & \multicolumn{2}{|c|}{0.388} & \multicolumn{2}{|c|}{0.253} \\
\hline \multicolumn{7}{|l|}{ Ornithine } \\
\hline DL-MET & 31 & 19 & 34 & 19 & 32 & 18 \\
\hline DL-HMTB & 28 & 26 & 24 & 16 & 26 & 22 \\
\hline$P$ & \multicolumn{2}{|c|}{0.738} & \multicolumn{2}{|c|}{0.210} & \multicolumn{2}{|c|}{0.303} \\
\hline \multicolumn{7}{|l|}{ Taurine } \\
\hline DL-MET & 26 & 21 & 24 & 15 & 25 & 18 \\
\hline DL-HMTB & 23 & 22 & 33 & 14 & 28 & 19 \\
\hline$P$ & \multicolumn{2}{|c|}{0.769} & \multicolumn{2}{|c|}{0.214} & \multicolumn{2}{|c|}{0.646} \\
\hline \multicolumn{7}{|l|}{ Urea } \\
\hline DL-MET & 858 & 458 & 1147 & 843 & 982 & 649 \\
\hline DL-HMTB & 610 & 499 & 1271 & 722 & 893 & 677 \\
\hline$P$ & \multicolumn{2}{|c|}{0.195} & \multicolumn{2}{|c|}{0.745} & \multicolumn{2}{|c|}{0.646} \\
\hline
\end{tabular}

also be ascribed to the increased catabolism of glutamate by the intestine. Because glutamine/glutamate and aspartate can also be converted to ornithine ${ }^{(24,25)}$, the increased first-pass metabolism of glutamate may account for the increased ornithine concentration in the arterial plasma of DL-HMTBfed pigs. Glutamate has been recognised to be a more important fuel than glucose for enterocytes, but the reason for DL-HMTB stimulating glutamate degradation by the intestine remains to be defined. Another interesting finding in the present study was that arterial taurine concentration was significantly higher in the DL-HMTB-fed than in the DL-MET-fed pigs. Consistent with the present results, DL-HMTB has been shown to be a more preferable source than L-methionine for taurine synthesis by isolated chick intestine ${ }^{(26)}$. Because the liver is demonstrated to be the major site for the trans-sulfuration of L-methionine to L-cysteine ${ }^{(27)}$, which can be then catabolised to taurine, the increased taurine concentration in the arterial vein may be an accumulative result of methionine trans-sulfuration in both the intestine and the liver. However, portal cysteine concentration or balance did not differ between the DL-HMTB-fed and the DL-MET-fed pigs ${ }^{(13)}$. As an explanation, this may be because small-intestinal cells are very active in the metabolism of dietary cysteine, because high levels of this amino acid adversely affect the viability of the enterocytes ${ }^{(28)}$. In contrast, taurine is the most abundant intracellular free amino acid ${ }^{(29)}$, possessing many protective cellular functions ${ }^{(26,30)}$.

A particularly important finding was that over all of the time courses evaluated, the average concentration of urea both in the arterial and portal plasma was substantially lower in the DL-HMTB group than in the DL-MET group. A previous study demonstrated that urea was formed from ammonia, glutamine and arginine in enterocytes from postweaning pigs ${ }^{(31)}$. In vivo studies have also shown that $33 \%$ of absorbed arginine was hydrolysed to urea plus ornithine in adult-rat jejunum ${ }^{(32)}$, indicating a substantial intestinal hydrolysis of arginine. Thus, the higher portal plasma urea concentration may provide further evidence for the higher first-pass intestinal metabolism of dietary arginine in the DL-MET than in the DL-HMTB diet ${ }^{(13)}$. The higher arterial plasma urea concentration could be explained by the fact that a major proportion of $\mathrm{N}$ derived from glutamine/ glutamate metabolism is converted to urea in the liver ${ }^{(33)}$. In addition, plasma urea concentration has been extensively used as a criterion to evaluate the $\mathrm{N}$ utilisation in single-stomached animals, because concentrations of urea $\mathrm{N}$ in plasma are directly related to the rate of urea synthesis and therefore inversely related to the efficiency of $\mathrm{N}$ deposition ${ }^{(34)}$. The evidence that urea synthesis occurs not only in the mammalian liver but also in the enterocytes ${ }^{(35)}$ provides a biological basis for the increased urea concentration both in portal and arterial plasma of the DL-MET-fed piglets. The decreased plasma urea concentration suggests the increased deposition of $\mathrm{N}$ in the DL-HMTB-fed piglets. In this regard, the present study may provide a biological support for superior $\mathrm{N}$ retention in DL-HMTB-fed pigs as observed in a previous study $^{(36)}$. Furthermore, it should be noted that the DL-HMTB molecule contains no $\mathrm{N}$ atom whereas the DL-MET molecule contains one $\mathrm{N}$ atom. It would appear that the catabolism of DL-MET might produce more plasma urea $\mathrm{N}$ than DL-HMTB metabolism. However, the same $\mathrm{N}$ content between the DL-MET and DL-HMTB diets (Table 1) may lower the effect of $\mathrm{N}$ deriving from methionine sources on urea synthesis. Collectively, the lower urea concentration in the arterial and portal plasma of the DL-HMTB-fed than in the DL-METfed pigs was largely associated with the difference in metabolism of some specific amino acids such as arginine and glutamate between the two diets.

A third endpoint in the present study was to examine whether the first-pass metabolism of dietary methionine sources by the intestine could influence the extra-intestinal availability of methionine in terms of the distribution of

Table 5. Isotopic enrichment (tracer:tracee ratio; mol/100 mol amino acid) of $\left[1-{ }^{13} \mathrm{C}\right]$ methionine in the jejunum, liver, kidney, muscle and arterial plasma of piglets fed DL-methionine (DL-MET) or DL-2-hydroxy-4-methylthiobutyrate (DL-HMTB) once hourly (Mean values and standard deviations)

\begin{tabular}{|c|c|c|c|c|c|c|c|c|c|c|}
\hline \multirow[b]{2}{*}{ Diet } & \multicolumn{2}{|c|}{ Jejunum } & \multicolumn{2}{|c|}{ Liver } & \multicolumn{2}{|c|}{ Kidney } & \multicolumn{2}{|c|}{ Muscle } & \multicolumn{2}{|c|}{ Arterial plasma } \\
\hline & Mean & SD & Mean & SD & Mean & SD & Mean & SD & Mean & SD \\
\hline DL-MET & $3 \cdot 13^{d}$ & 0.32 & $3.49^{c, d}$ & 0.25 & $3.86^{b, c}$ & 0.33 & $4 \cdot 19^{b}$ & 0.20 & $5.46^{\mathrm{a}}$ & 0.36 \\
\hline DL-HMTB & $3 \cdot 00^{d}$ & $0 \cdot 14$ & $3.87^{c}$ & 0.20 & $3 \cdot 81^{c}$ & 0.32 & $4.57^{b}$ & 0.15 & $5 \cdot 77^{\mathrm{a}}$ & 0.37 \\
\hline$P$ & \multicolumn{2}{|c|}{0.55} & \multicolumn{2}{|c|}{0.10} & \multicolumn{2}{|c|}{0.80} & \multicolumn{2}{|c|}{0.10} & \multicolumn{2}{|c|}{0.21} \\
\hline
\end{tabular}

a,b,c,d Mean values within a row with unlike superscript letters were significantly different $(P<0.05)$. 
tracer methionine in the piglets. The results indicated that the tracer methionine enrichment in the muscle was lower than that in the plasma, but higher than that in the other tissues evaluated, suggesting that the major proportion of dietary methionine is utilised for protein synthesis. In contrast to the highest tracer methionine enrichment in the portal plasma among blood and tissues currently evaluated, in a previous study $^{(37)}$ in which DL- $\left[1-{ }^{13} \mathrm{C}\right]$ HMTB was infused into the abomasum to trace the metabolism of DL-HMTB in lambs, the highest tracer methionine $\left(\left[1-{ }^{13} \mathrm{C}\right]\right.$ methionine) enrichment was observed in the arterial plasma and kidney. The relatively lower capacity of the intestine and the substantially higher capacity of the liver and kidney to convert DL-HMTB to Lmethionine ${ }^{(11)}$ may provide an explanation for the lower and higher $\left[1-{ }^{13} \mathrm{C}\right]$ methionine enrichment in the portal and arterial plasma, respectively, following DL- $\left[1-{ }^{13} \mathrm{C}\right] \mathrm{HMTB}$ infusion. This notion was further supported by the fact that recovery of DL-HMTB at the portal vein was $87 \%$, and, of this, $63 \%$ bypassed the liver ${ }^{(37)}$. Furthermore, the extraction of methionine by visceral tissues has been shown to be lower in the intestine than in the liver ${ }^{(37)}$, which may account for the higher tracer methionine enrichment in the portal vein than in the arterial vein following gastric infusion of $\left[1-{ }^{13} \mathrm{C}\right] \mathrm{methionine}$ in the present study. The observation that it was $1 \mathrm{~h}$ later for arterial methionine concentration than for portal methionine concentration to approach statistical difference from the baseline (Fig. 2) may also be a result of less extraction of methionine by the intestine than by the liver. The considerable enrichments of tracer methionine in the kidney, liver and jejunum may be associated with the remethylation of systematic homocysteine to methionine, because numerous studies have shown that the splanchnic tissues including the liver, kidney and jejunum are the major sites for remethylation of systematic homocysteine ${ }^{(20,38-40)}$. The numerically $(P=0 \cdot 10)$ higher tracer methionine enrichment in the muscle of the DLHMTB group than that of the DL-MET group may imply a positive effect of DL-HMTB on protein deposition, given evidence that the trans-sulfuration reaction in the muscle is quantitatively low ${ }^{(17)}$. Consistent with this notion is the finding that tracer methionine was undetectable in the supernatant fraction of the muscle homogenate after tracer infusion ${ }^{(41)}$.

In summary, the present study suggested that the potential difference in the first-pass use of methionine by the intestine between the DL-HMTB and DL-MET diets might affect the intestinal and systemic metabolism of other amino acids, which may provide new important insights into nutritional efficiency of different methionine sources.

\section{Acknowledgements}

The present research was supported in part by the National Natural Science Foundation of China (30771560), the National High-tech Research and Development Program (2006AA10Z140) and Wuhan Municipal Projects of Industrialization of Science and Technology (200720112026). The authors thank ADISSEO France S.A.S. for partial financial support (Rhodimet Research Grant 2008-2010: The first-pass metabolism and extraintestinal availability of dietary methionine).
Z. F., J. P. and S. J. designed the research; Z. F., F. H., J. L., H. W. and L. M. performed the research; Z. F., J. P. and S. J analysed the data and wrote the paper.

The authors declare no conflict of interest.

\section{References}

1. Wu G, Knabe DA \& Flynn NE (2005) Amino acid metabolism in the small intestine: biochemical bases and nutritional significance. In Biology of Metabolism in Growing Animals, pp. 107-126 [DG Burrin and HJ Mersmann, editors]. London: Elsevier Science.

2. Madara JL (1991) Functional morphology of epithelium of the small intestine. In Handbook of Physiology: The Gastrointestinal System, pp. 83-120 [SG Shultz, editor]. Bethesda, MD: American Physiological Society.

3. Stoll B, Henry J, Reeds PJ, et al. (1998) Catabolism dominates the first-pass intestinal metabolism of dietary essential amino acids in milk protein-fed piglets. $J$ Nutr 128, 606-614.

4. Wu G (1998) Intestinal mucosa amino acid metabolism. J Nutr 128, 1249-1252.

5. van der Schoor SR, van Goudoever JB, Stoll B, et al. (2001) The pattern of intestinal substrate oxidation is altered by protein restriction in pigs. Gastroenterology 121, 1167-1175.

6. Van Goudoever JB, Stoll B, Henry JF, et al. (2000) Adaptive regulation of intestinal lysine metabolism. Proc Natl Acad Sci U S A 97, 11620-11625.

7. Bos C, Stoll B, Fouillet H, et al. (2003) Intestinal lysine metabolism is driven by the enteral availability of dietary lysine in piglets fed a bolus meal. Am J Physiol Endocrinol Metab 285, E1246-E1257.

8. Burrin DG, Stoll B, Chang X, et al. (1999) Total parenteral nutrition does not compromise digestion or absorption of dietary protein in neonatal pigs. FASEB $J \mathbf{1 3}, \mathrm{A} 1024$.

9. Bertolo RFP, Pencharz PB \& Ball RO (2005) Role of intestinal first-pass metabolism on whole-body amino acid requirements. In Biology of Metabolism in Growing Animals, pp. 127-156 [DG Burrin and HJ Mersmann, editors]. London: Elsevier Science.

10. Dibner JJ \& Ivey FJ (1992) Capacity in the liver of the broiler chick for conversion of supplemental methionine activity to L-methionine. Poult Sci 71, 1695-1699.

11. Dibner JJ \& Knight CD (1984) Conversion of 2-hydroxy-4(methylthio)butanoic acid to L-methionine in the chick: a stereospecific pathway. J Nutr 114, 1716-1723.

12. National Research Council (1998) Nutrient Requirements of Swine, 10th ed. Washington, DC: National Academic Press.

13. Fang ZF, Luo J, Qi ZL, et al. (2009) Effects of 2-hydroxy-4methylthiobutyrate on portal plasma flow and net portal appearance of amino acids in piglets. Amino Acids 36, 501-509.

14. Yen JT \& Killefer J (1987) A method for chronically quantifying net absorption of nutrients and gut metabolites into hepatic portal vein in conscious swine. J Anim Sci 64, 923-934.

15. Tappenden KA, Drozdowski LA, Thomson ABR, et al. (1998) Short-chain fatty acid-supplemented total parenteral nutrition alters intestinal structure, glucose transporter 2 (GLUT2) mRNA and protein, and proglucagon mRNA abundance in normal rats. Am J Clin Nutr 68, 118-125.

16. McCollum MQ, Vázquez-Añón M, Dibner JJ, et al. (2000) Absorption of 2-hydroxy-4-(methylthio)butanoic acid by isolated sheep ruminal and omasal epithelia. J Anim Sci 78, 1078-1083.

17. Riedijk MA, Stoll B, Chacko S, et al. (2007) Methionine transmethylation and transsulfuration in the piglet gastrointestinal tract. Proc Natl Acad Sci U S A 104, 3408-3413. 
18. Pietzsch J, Julius U \& Hanefeld M (1997) Rapid determination of total homocysteine in human plasma by using $\mathrm{N}(\mathrm{O}, \mathrm{S})$-ethoxycarbonyl ethyl ester derivatives and gas chromatography-mass spectrometry. Clin Chem 43, 2001-2004.

19. Husek P (1991) Amino acid derivatization and analysis in five minutes. FEBS Lett 280, 354-356.

20. Storch KJ, Wagner DA, Burke JF, et al. (1988) Quantitative study in vivo of methionine cycle in humans using [methyl- $\left.{ }^{2} \mathrm{H}_{3}\right]-$ and $\left[1-{ }^{13} \mathrm{C}\right]$ methionine. Am J Physiol 255, E322-E331.

21. Wu G (1997) Synthesis of citrulline and arginine from proline in enterocytes of postnatal pigs. Am J Physiol Gastrointest Liver Physiol 272, G1382-G1390.

22. Wu G, Knabe DA \& Flynn NE (1994) Synthesis of citrulline from glutamine in pig enterocytes. Biochem $J$ 299, 115-121.

23. Dhanakoti SN, Brosnan JT, Herzberg GR, et al. (1990) Renal arginine synthesis: studies in vitro and in vivo. Am J Physiol 259, E437-E442.

24. Windmueller HG \& Spaeth AE (1975) Intestinal metabolism of glutamine and glutamate from the lumen as compared to glutamine from blood. Arch Biochem Biophys 171, 662-672.

25. Stoll B, Burrin DG, Henry J, et al. (1999) Substrate oxidation by the portal drained viscera of fed piglets. Am J Physiol 277, E168-E175.

26. Martín-Venegas R, Geraert PA \& Ferrer R (2006) Conversion of the methionine hydroxy analogue DL-2-hydroxy-(4-methylthio) butanoic acid to sulfur-containing amino acids in the chicken small intestine. Poult Sci 85, 1932-1938.

27. Stipanuk MH, Londono M, Lee JI, et al. (2002) Enzymes and metabolites of cysteine metabolism in nonhepatic tissues of rats show little response to changes in dietary protein or sulfur amino acid levels. J Nutr 132, 3369-3378.

28. Coloso RM \& Stipanuk MH (1989) Metabolism of cyst(e)ine in rat enterocytes. J Nutr 119, 1914-1924.

29. O'Flaherty L, Stapleton PP, Redmond HP, et al. (1997) Intestinal taurine transport: a review. Eur J Clin Invest 27, 873-880.
30. Lambert IH (2004) Regulation of the cellular content of the organic osmolyte taurine in mammalian cells. Neurochem Res 29, 27-63.

31. Wu G, Knabe DA, Yan W, et al. (1995) Glutamine and glucose metabolism in enterocytes of the neonatal pig. Am J Physiol 268, R334-R342.

32. Windmueller HG \& Spaeth AE (1976) Metabolism of absorbed aspartate, asparagine, and arginine by rat small intestine in vivo. Arch Biochem Biophys 175, 670-676.

33. Reeds PJ, Burrin DG, Stoll B, et al. (2000) Intestinal glutamate metabolism. J Nutr 130, 978S-982S.

34. Coma J, Zimmerman DR \& Carrion D (1995) Relationship of rate of lean tissue growth and other factors to concentration of urea in plasma of pigs. J Anim Sci 73, 3649-3656.

35. Wu G (1995) Urea synthesis in enterocytes of developing pigs. Biochem J 312, 717-723.

36. Römer A \& Abel HJ (1999) Effects of DL-methionine hydroxyanalogue (MHA) or DL-methionine (DL-Met) on N-retention in broiler chickens and pigs. Anim Feed Sci Technol 81, 193-203.

37. Lobley GE, Wester TJ, Calder AG, et al. (2006) Absorption of 2-hydroxy-4-methylthiobutyrate and conversion to methionine in lambs. J Dairy Sci 89, 1072-1080.

38. Storch KJ, Wagner DA, Burke JF, et al. (1990) $\left[1-{ }^{13} \mathrm{C}\right.$; methyl- $\left.{ }^{2} \mathrm{H}_{3}\right]$ methionine kinetics in humans: methionine conservation and cystine sparing. Am J Physiol 258, E790-E798.

39. Park EI \& Garrow TA (1999) Betaine-homocysteine methyltransferase: interaction between methionine and methyl donor intake on rat liver gene expression and organization of the human gene. J Biol Chem 274, 7816-7824.

40. Rowling MJ, McMullen MH, Chipma DC, et al. (2002) Hepatic glycine $\mathrm{N}$-methyltransferase is upregulated by excess dietary methionine in rats. J Nutr 132, 2545-2550.

41. Lobley GE, Connell A \& Revell D (1996) The importance of transmethylation reactions to methionine metabolism in sheep: effects of supplementation with creatine and choline. $\mathrm{Br} \mathrm{J}$ Nutr 75, 47-56. 